\title{
Fiber-optic temperature measurements in closed-loop geothermal systems: A case study in heterogeneous bedrock
}

\author{
G. Radioti, S. Delvoie, K. Sartor, F. Nguyen \& R. Charlier \\ University of Liege, Liege, Belgium
}

\begin{abstract}
In order to study the behaviour of shallow closed-loop geothermal systems, four borehole heat exchangers equipped with fiber optics were installed on the campus of the University of Liege (Liege, Belgium) over a surface area of $32 \mathrm{~m}^{2}$. This paper presents continuous, high-resolution temperature profiles measured along the boreholes length at different phases: at the undisturbed state, during hardening of the grouting material, during the recovery phase of a Distributed Thermal Response Test (DTRT) and during a DTRT of a long duration (7 months). The undisturbed ground temperature is affected by the heat loss from ground structures located close to the boreholes, as also indicated by a 3D numerical model. Temperature profiles during hardening of the grouting material indicate extended fractured zones in the rock mass. Temperature measurements during the recovery phase can be correlated to rock layers with different mineral content. The results are in good agreement with those of the borehole televiewer logging method. The long duration DTRT allow us to follow the thermal plume in the heterogeneous rock mass. Moreover the effect of the duration of the test to the calculated mean thermal conductivity and borehole thermal resistance is investigated. The presented analysis could provide information on bedrock heterogeneity, on the anisotropic thermal behaviour of the rock mass and on the ground temperature variations due to heat loss from ground structures. These information could significantly contribute to the long-term behaviour prediction of the geothermal system and the geothermal reservoir potential.
\end{abstract}

\section{INRODUCTION}

In order to study the behaviour of closed-loop geothermal systems in heterogeneous bedrock, four Borehole Heat Exchangers (BHEs), namely B1 to B4, were installed on the campus of the University of Liege (Liege, Belgium) over a surface area of $32 \mathrm{~m}^{2}$ (Radioti et al. 2013). The four BHEs, equipped with double$\mathrm{U}$ geothermal pipes of $100 \mathrm{~m}$ long are located at a distance of approximately $15 \mathrm{~m}$ to a building (SEGI) and $6.6 \mathrm{~m}$ to an underground structure (feeder pipe) (Fig. 1).

After drilling the boreholes, a borehole televiewer was lowered inside the four boreholes. A detailed bedrock characterisation was conducted based on acoustic borehole imaging data, gamma-ray logging data and cuttings observation (Radioti et al. 2015a).

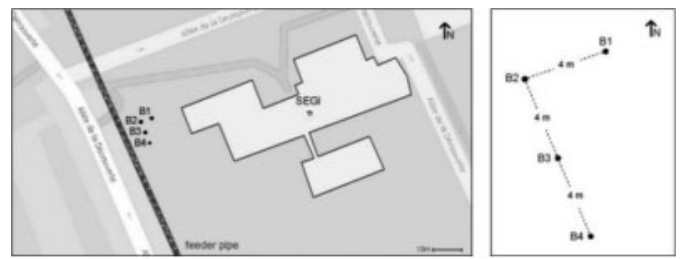

Figure 1. Site location on the campus of the University of Liege (Liege, Belgium).
The site geology is characterised by deposits of sand and gravel until a depth of approximately $8 \mathrm{~m}$. The bedrock follows which consists mainly of siltstone and shale interbedded with sandstone. Fractured zones are detected in the rock mass mainly until a depth of $35 \mathrm{~m}$. The mean layer dip angle is approximately $45^{\circ} \mathrm{SE}$. Moreover, azimuth and deviation were measured by magnetometers and inclinometers (Monier-Williams et al. 2009). Based on these data, the horizontal distance through depth between $\mathrm{B} 2$ and the other three boreholes was estimated and presented in Figure 2. B1 and B2 are characterised by roughly the same lithostratigraphy, which is observed at different depths in B3 and B4, due to the layer dip angle orientation. The distance through depth between $\mathrm{B} 1$ and $\mathrm{B} 2$ oscillates around $4.1 \mathrm{~m}$. The distance between $\mathrm{B} 2$ and $\mathrm{B} 3$ or B4 decreases through depth, becoming almost the half at the bottom of the boreholes.

During the installation of the geothermal pipes, fiber optic cables were attached along the pipe loops. Fiber optics allows us to obtain continous, highresolution temperature profiles along the pipes length by applying the DTS technique (Hermans et al. 2014). This technique is based on Raman optical time domain reflectometry. The fiber ends are connected to the DTS instrument, which injects a laser pulse. The light travels into the optical fiber and is scattered and reemitted from the observed point. The backscattered light is spread across a range of wavelengths. 


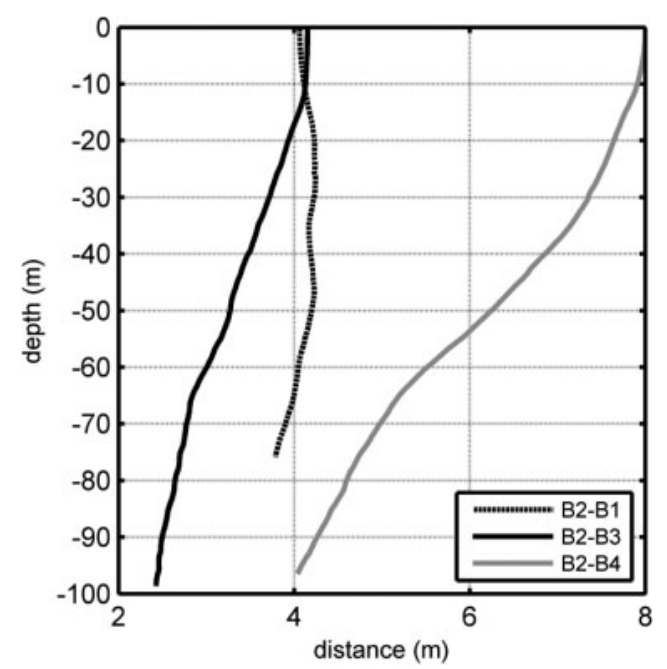

Figure 2. Horizontal distance between B2 and the other three boreholes.

The Raman backscatter signal is temperature sensitive. The temperature along the fiber is determined by the intensity of Raman Stokes and anti-Stokes signals. The position of the temperature reading is determined by the arrival time of the reemitted light pulse. The temperature resolution (standard deviation) of the DTS instrument used in this study is in the order of $0.05^{\circ} \mathrm{C}$. Temperature was recorded every $20 \mathrm{~cm}$ (sampling interval) with a spatial resolution of $2 \mathrm{~m}$. Spatial resolution determines the slope width of a measured temperature change and is an important parameter for the temperature accuracy of local hotspots. If the width of the hotspot is lower than the spatial resolution, the measured temperature is reduced by approximately the ratio of hotspot width to spatial resolution (Hoffman et al. 2007).

The boreholes were backfilled with the following grouting materials: $\mathrm{B} 1$ and $\mathrm{B} 3$ with a silica sand-based commercial material (Geosolid, $\lambda=2.35 \mathrm{~W} / \mathrm{mK}$ ), B2 with a bentonite-based commercial material (Füllbinder, $\lambda=0.95 \mathrm{~W} / \mathrm{mK}$ ) and B4 with a homemade admixture with graphite $(\lambda=2.5 \mathrm{~W} / \mathrm{mK})$ (Erol \& François 2014).

Temperature was measured at the undisturbed state, during hardening of the grouting material and during Distributed Thermal Response Tests (DTRT) (Fujii et al. 2006) conducted in situ in the four BHEs. At each depth position two temperature measurements were available, since the fiber optic cables were attached in a loop along the pipes. The temperature profiles presented hereafter correspond to the average of the these two measurements.

\section{UNDISTURBED GROUND TEMPERATURE}

Temperature was measured at the undisturbed state several times in a period of 2 years (Fig. 3). The first

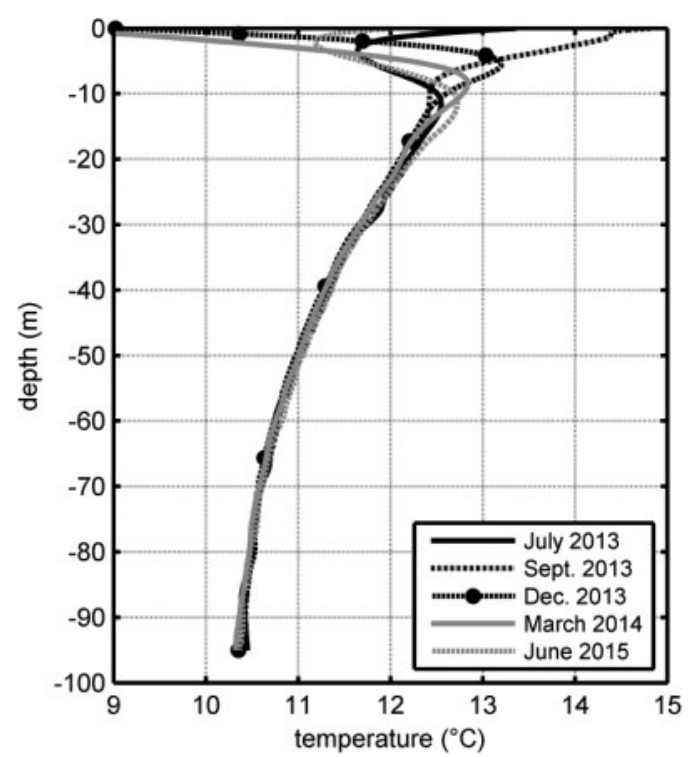

Figure 3. Undisturbed ground temperature measured by fiber optics in B2.

approximately $18 \mathrm{~m}$ correspond to the thermally unstable zone, where ground temperature is influenced by the air temperature. Below $18 \mathrm{~m}$, measured temperatures appear invariant to time in the two-years period and the temperature decreases through depth at a mean rate of approximately $0.25^{\circ} \mathrm{C} / 10 \mathrm{~m}$, opposite to the geothermal gradient effect.

A 3D numerical model was developed, by using the finite element code LAGAMINE (Charlier et al. 2001, Collin et al. 2002), to investigate if the measured ground temperature profiles could be a result of the heating of the ground due to structures heat loss into the subsurface (Radioti et al. 2015b). This model takes into account the heat loss through the basement of the SEGI building and through the shell of the feeder pipe. The feeder is simulated with a surface heating element. The heat loss $(150 \mathrm{~W} / \mathrm{m}$ length $)$ is calculated based on temperature measurements inside the feeder pipes (Sartor et al. 2014). The heat loss through the foundations of the SEGI building is simulated by imposing a constant temperature through time $\left(17.7^{\circ} \mathrm{C}\right)$ at the whole building surface, as measured by temperature data loggers at the basement of the building. The initial ground temperature (before the presence of engineering structures, in 1970) is calculated analytically based on air temperature data and on the ground thermal properties (Tinti 2012). The air temperature parameters used in this calculation are based on statistical data for the Sart-Tilman area for a period of 20 years (climate-data.org) and the mean ground thermal conductivity on Thermal Response Tests (TRTs) conducted in situ in the four boreholes. In this model the simplified assumptions are made that at bare ground the temperature is constant through time, equal to the average annual air temperature, and 


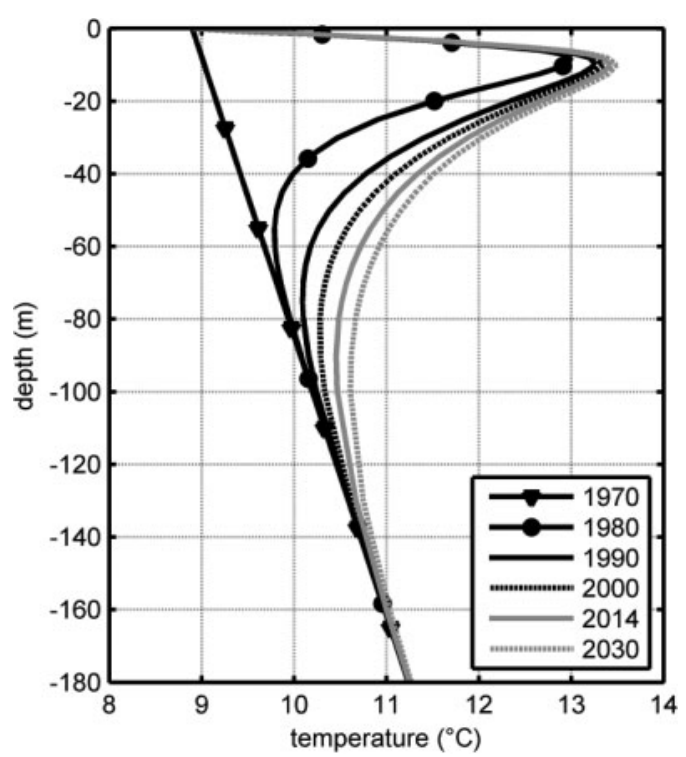

Figure 4. Numerical results of ground temperature at the location of the boreholes.

that the ground surface under the pavement can be simulated by a no-heat-flux boundary condition.

The numerical results of the ground temperature are presented in Figure 4.The geothermal gradient effect is evident in the temperature profile for the year 1970, which corresponds to the ground temperature before the presence of engineering structures. The heating of the ground, due to the feeder and the SEGI building operation, modifies the temperature gradient at the boreholes location until a depth of $100 \mathrm{~m}$ after 20 years (1990). The heating effect becomes progressively evident at greater depth, reaching a depth of $130 \mathrm{~m}$ after 45 years (2015). Moreover, the numerical results for the first $100 \mathrm{~m}$ are in good agreement with the temperature profiles measured by the fiber optics for the measurement period (2013-2015).

Figures 5 shows the temperature profiles in 2014 measured by the fiber optics in the four boreholes. The temperature profiles in B2, B3 and B4 coincide with each other and display a higher temperature in the first $20 \mathrm{~m}$ compared to B1. This could be attributed to the distance of each borehole from the feeder pipe, which is located at an average depth of $2.5 \mathrm{~m}$. Given that B2, $\mathrm{B} 3$ and $\mathrm{B} 4$ are $4 \mathrm{~m}$ closer to the feeder pipe than $\mathrm{B} 1$, the heat loss effect from the feeder pipe will be more enhanced in theese three boreholes. This effect is also observed in the numerical analysis results presented in Figure 6.

\section{DURING HARDENING OF THE GROUTING MATERIAL}

Figure 7 shows the temperature profile measured one day after injecting the grouting material in B4. Heat is generated during the first hours of hardening of

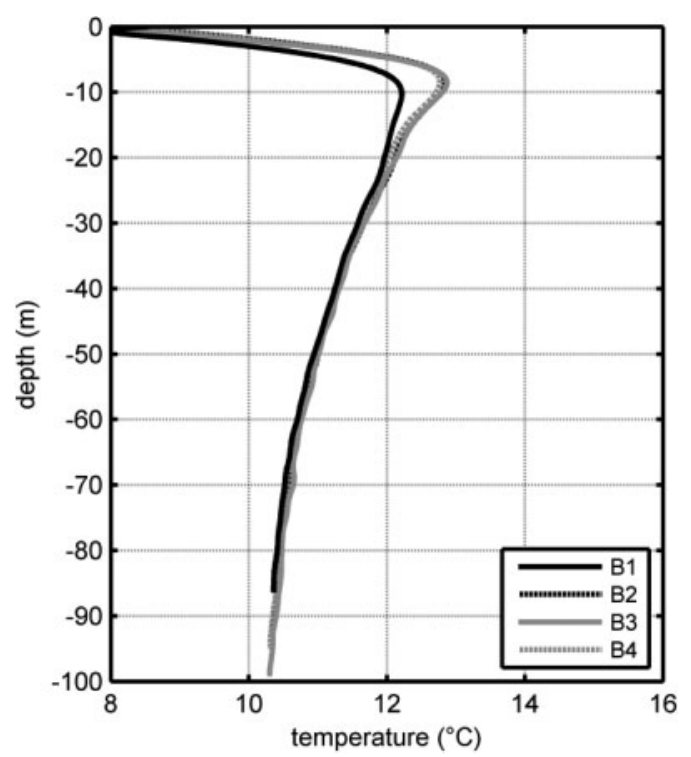

Figure 5. Temperature profiles measured by the fiber optics in the four boreholes in 2014.

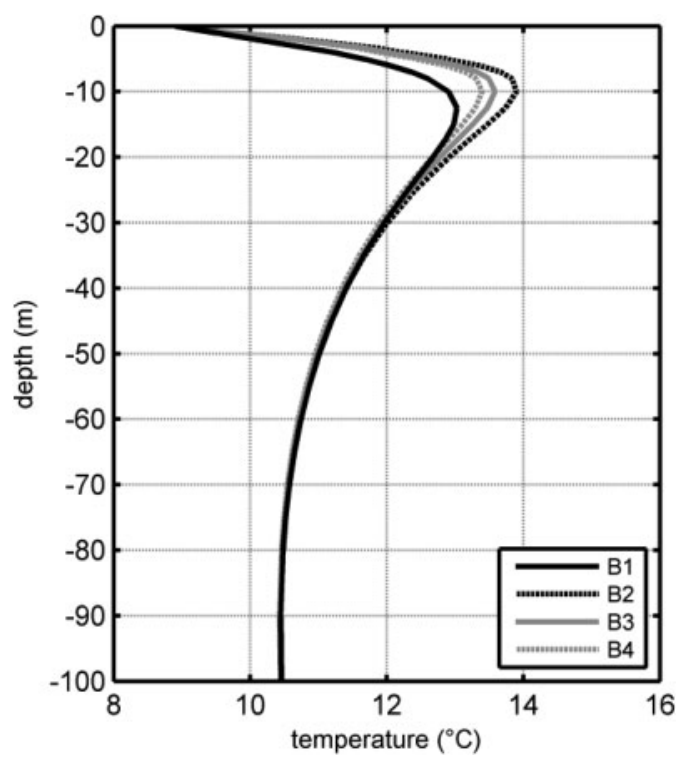

Figure 6. Numerical results of ground temperature at the location of the four boreholes for the year 2014 .

the grouting material, which results in a temperature increase along the borehole length. In the following days temperature retrieves its initial undisturbed profile. In the first $18 \mathrm{~m}$ temperature is influenced by the air temperature. Below $18 \mathrm{~m}$, the profile during hardening of the grouting material is characterised by a local maxima, of a significantly increased temperature value, at $29 \mathrm{~m}$. This location corresponds to an extended fractured zone, more than one meter thick, based on the borehole televiewer data analysis. 


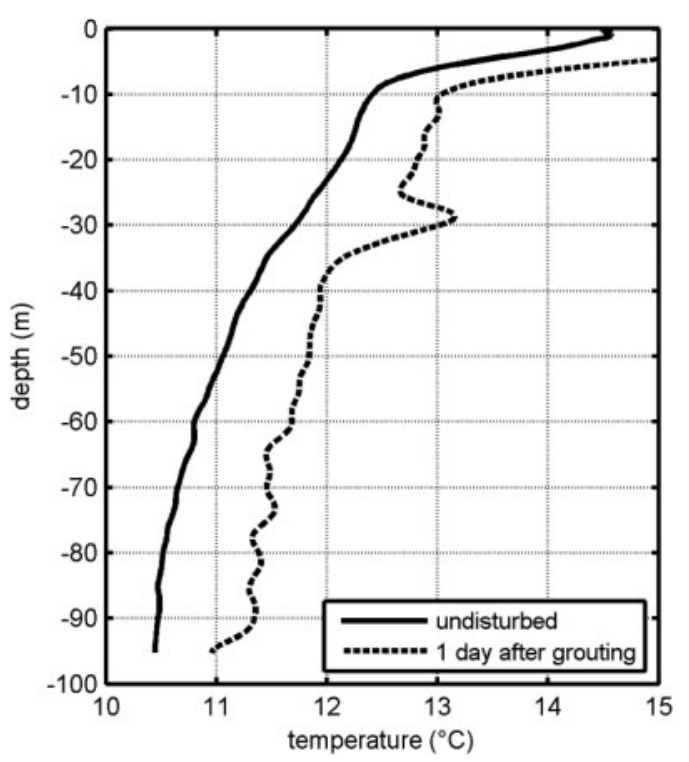

Figure 7. Temperature profiles at the undisturbed state and during hardening of the grouting material in B4.

The local maxima could be attributed to a local larger quantity of grouting material and/or local lower thermal diffusivity due to gathering of fractures. A local maxima is also observed in the profile of B1, at a depth corresponding to the center of an extended fractured zone (Radioti et al. 2015a).

Random large fractures (more than $10 \mathrm{~cm}$ wide) or smaller fractures (of an opening between 5 and $10 \mathrm{~cm}$ ) cannot be identified in the profiles during hardening of the groutting material in this case-study This could be attributed to the width of hotspots corresponding to random fractures, which is lower than the spatial resolution $(2 \mathrm{~m})$ and sampling interval $(20 \mathrm{~cm})$.

\section{DURING THE RECOVERY PHASE OF A DTRT}

Figure 8 (right) presents the naturally occurring gamma radiation data (moving average of $2 \mathrm{~m}$ ) for $\mathrm{B} 3$, which were measured to characterise the clay content of the rock formation. High gamma-ray values indicate shale/siltstone layers while low gamma-ray values indicate sandstone/siltstone layers. Figure 8 (left) presents the temperature difference between a recovery profile (after $4 \mathrm{~h}$ of recovery) and the undisturbed temperature profile for B3. Local peaks in this profile indicate an uneven heat transfer rate through depth.

It is observed that temperature local minima correspond to gamma-ray local minima, indicating sandstone/siltstone layers, while temperature local maxima to gamma-ray local maxima, indicating shale/siltstone layers. The higher thermal diffusivity of
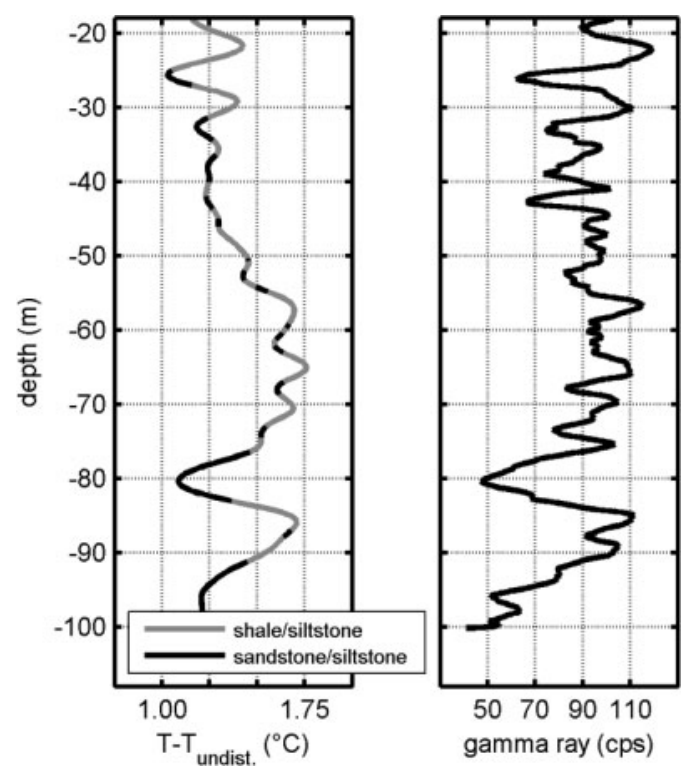

Figure 8 . Temperature difference after $4 \mathrm{~h}$ of recovery and natural gamma radioactivity data for B3.

sandstone/siltstone is evident in the in-situ measurements despite the relatively small thickness of these layers.

Sandstone/siltstone layers thinner than $1.2 \mathrm{~m}$ are not always detectable in the recovery profile. The width of hotspots corresponding to these layers is lower than the measurements spatial resolution $(2 \mathrm{~m})$ and the sampling interval $(20 \mathrm{~cm})$. Even if these hotspots were included in the measurement points, the measured temperature could be significantly reduced, and hence be undetectable in the temperature profile.

\section{DURING THE HEATING PHASE OF A LONG-DURATION DTRT}

A TRT of a heating phase of 7 months was conducted in B2. During this test, temperature is measured at the pipe inlet and outlet in B2, as well as by the fiber optics in the four boreholes. These measurements allow to investigate the behaviour of the BHE in B2 through time and to follow the thermal plume in the heterogeneous rock mass.

\subsection{Mean ground thermal conductivity and mean borehole thermal resistance}

The mean thermal conductivity of the surrounding ground and the mean borehole thermal resistance were calculated based on the pipe inlet and outlet temperature data in B2. The Infinite Line Source model (Carslaw \& Jaeger 1959) was used for this calculation and the forward regression technique was applied (Tinti 2012). In this technique a start time point is chosen and the end time point increases gradually. During 


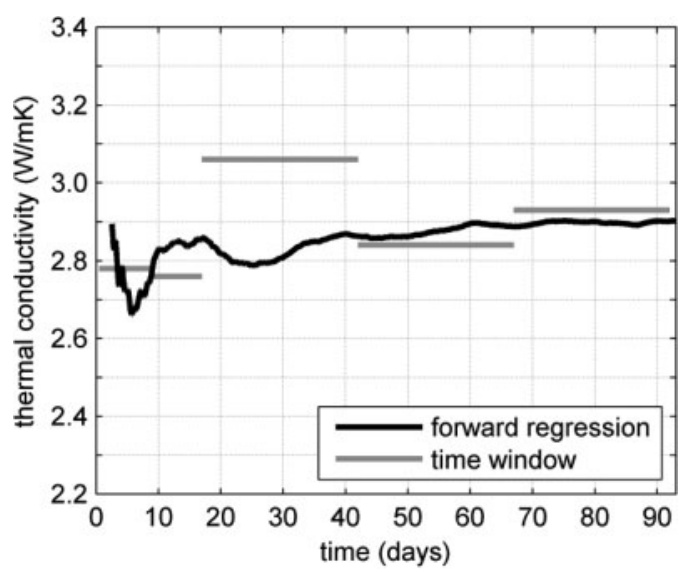

Figure 9. Mean ground thermal conductivity through time for the first 3 months of the heating phase in B2.

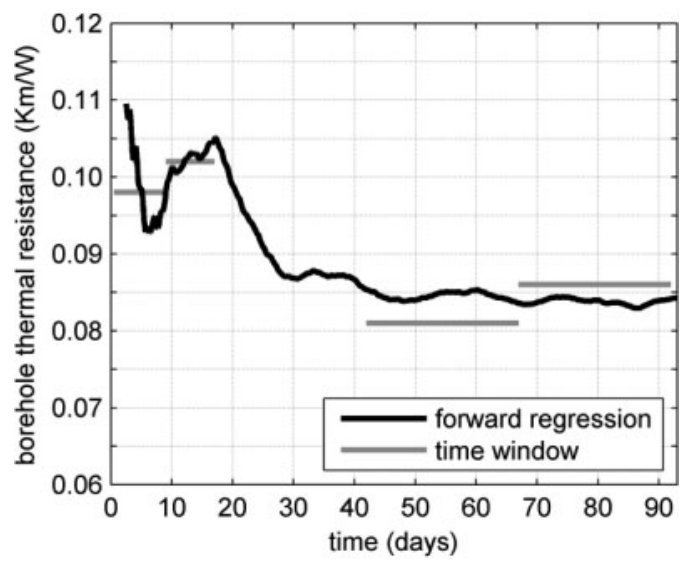

Figure 10. Mean borehole thermal resistance through time for the first 3 months of the heating phase in B2.

the first few hours of the test, the temperature evolution is mainly controlled by the borehole filling and is not representative of the surrounding rock thermal properties (Sanner et al. 2005). A start time point of $10 \mathrm{~h}$ was chosen for this analysis, based on optical crosschecking of the measured data. Thermal conductivity and borehole thermal resistance were also evaluated for data in limited time windows.

Figures 9 shows the calculated mean thermal conductivity for the first three months of the test. The obtained thermal conductivity values range from $2.66 \mathrm{~W} / \mathrm{mK}$ to $3.06 \mathrm{~W} / \mathrm{mK}$ (difference less than $15 \%$ ) based on the two techniques for the period of 3 months.

Figures 10 shows the calculated mean borehole thermal resistance for the first three months of the test. The borehole thermal resistance ranges from $0.093 \mathrm{Km} / \mathrm{W}$ to $0.11 \mathrm{Km} / \mathrm{W}$ for the first 20 days. Between 20 days and 30 days the thermal resistance decreases of $17 \%$ and it converges around a value of $0.085 \mathrm{Km} / \mathrm{W}$ for the rest of the time period.
Table 1. Mean ground thermal conductivity and mean borehole thermal resistance for the four BHEs.

\begin{tabular}{llll}
\hline & $\lambda_{\text {grout }}^{*}$ & $\mathrm{R}_{\mathrm{b}}$ & $\lambda_{\text {ground }}$ \\
\hline BHE (grouting) & $\mathrm{W} / \mathrm{mK}$ & $\mathrm{Km} / \mathrm{W}$ & $\mathrm{W} / \mathrm{mK}$ \\
\hline B1 (Geosolid) & 2.35 & 0.079 & 2.94 \\
B2 (Füllbinder) & 0.95 & 0.095 & 2.71 \\
B3 (Geosolid) & 2.35 & 0.078 & 3.09 \\
B4 (Hom. admixture) & 2.46 & 0.080 & 2.80 \\
\hline
\end{tabular}

* Erol \& François 2014.

Table 1 presents ground thermal conductivity and borehole thermal resistance results, based on TRTs of a duration of 7 days conducted in the four BHEs. The average ground thermal conductivity is $2.88 \pm 0.16 \mathrm{~W} / \mathrm{mK}$. The Geosolid admixture and the homemade admixture with graphite display approximately the same thermal conductivity and the corresponding BHEs are characterised by a borehole thermal resistance in the order of $0.08 \mathrm{Km} / \mathrm{W}$. The Füllbinder admixture (B2) has a lower thermal conductivity and the corresponding thermal resistance is $19 \%$ higher than the other three BHEs. Though the borehole thermal resistance in B2 decreases with time for a longer duration of the heating phase, as presented previously in Figure 10.

\subsection{Temperature evolution in the rock mass}

Figure 11 displays the temperature increase through time in the four boreholes. Data for B2 correspond to the mean temperature of the pipe inlet and outlet. Data for the other three boreholes correspond to the depth-average temperature measured by the fiber optics. Temperature starts to increase after approximately 5 days in B3, 10 days in B1 and 16 days in B4. Temperature increases at a higher rate in $\mathrm{B} 3$ than the other two boreholes, since this borehole has the smallest distance to B2. Likewise, the lowest increase rate is observed in B4 which is located at the greatest distance to B2. These measurements illustrate the effect of the distance to the heating source on the temperature evolution in the rock mass.

Figure 12 shows temperature measured in B3 during the heating phase of the DTRT in B2. The first approximately $18 \mathrm{~m}$ are influenced by the air temperature. Temperature starts to increase at the lower part of the borehole, since this part has a smaller distance to $\mathrm{B} 2$ than the upper part and is characterised by thick sandstone layers.

Figure 13 shows the temperature increase evolution at a depth location of $77.2 \mathrm{~m}$, which corresponds to a local maxima in the temperature profile, and at a depth location of $82.8 \mathrm{~m}$, which corresponds to a local minima of the temperature profile. These locations have approximately the same distance to B2. The temperature difference between the two profiles increases with time, reaching an order of magnitude of $0.3^{\circ} \mathrm{C}$ after 90 

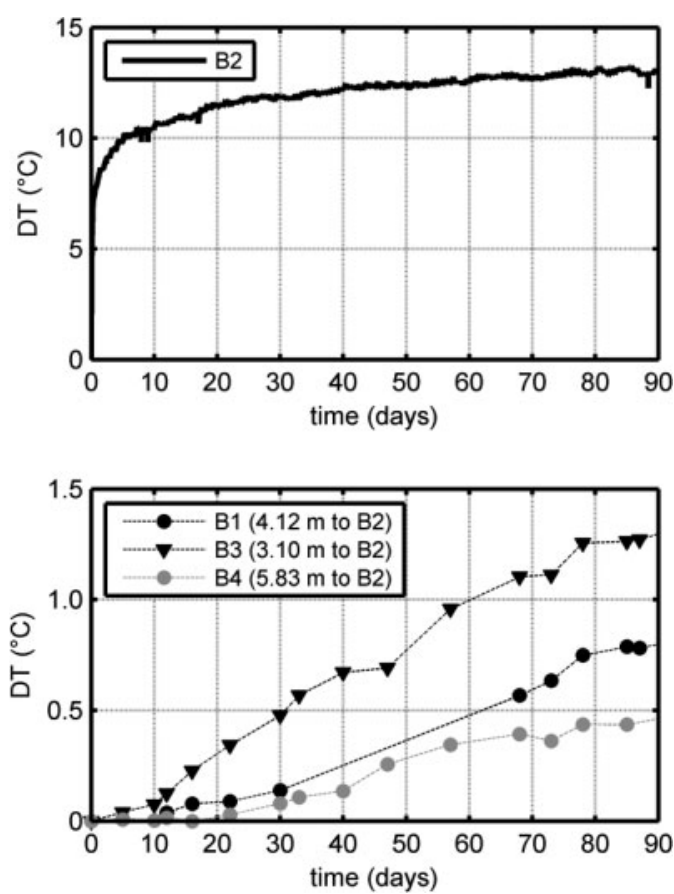

Figure 11. Temperature evolution in the four BHEs (B2: mean of pipe inlet and outlet temperature - B1,B3,B4: depth-average temperature by fiber optics).

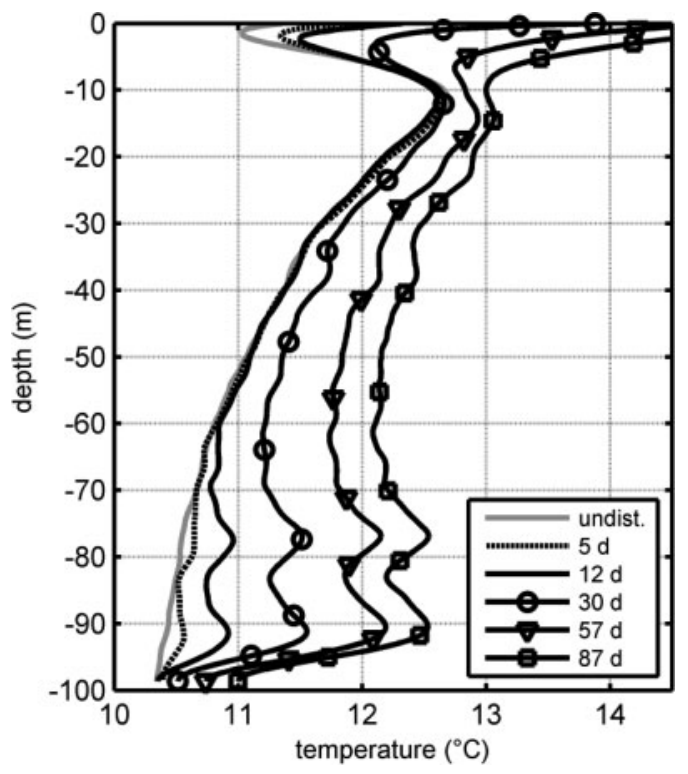

Figure 12. Temperature profiles in B3 during the heating phase of the DTRT in B2.

days. This indicates a higher heat transfer rate at the location of the local maxima, compared to the one of the local minima.

Figure 14 presents the temperature difference between the temperature profile after 78 days and the

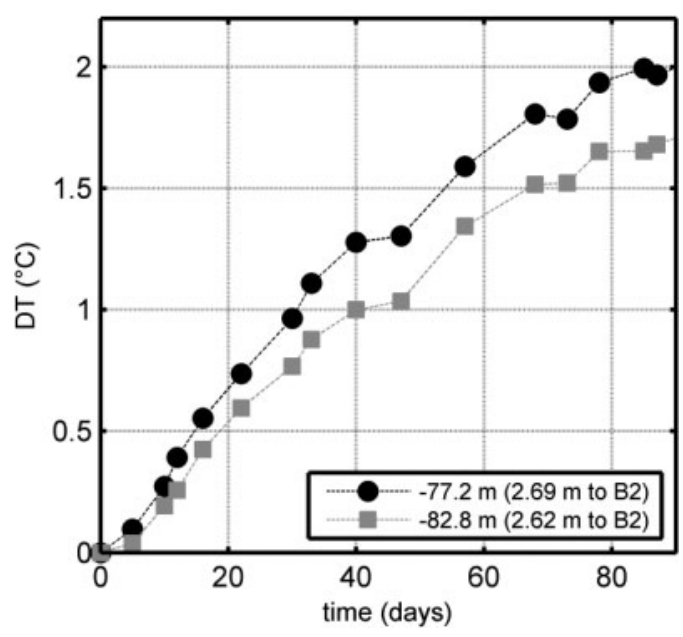

Figure 13. Temperature increase evolution at certain depths in B3.
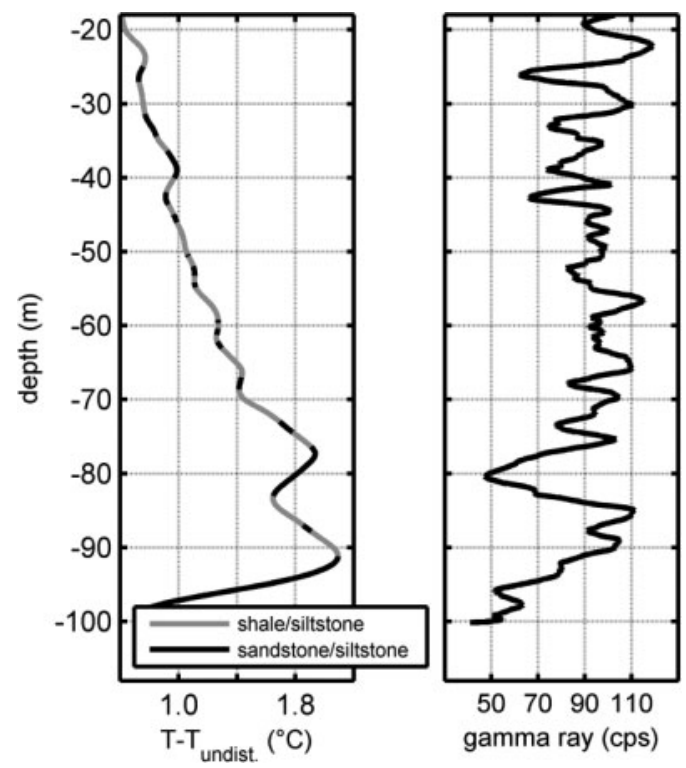

Figure 14. Temperature difference after 78 days of heating and natural gamma radioactivity data for B3.

undisturbed temperature profile (left), together with the gamma-ray data for B3. It is observed that the local maxima at $77.2 \mathrm{~m}$ depth corresponds to the top of a sandstone/siltstone layer and the local minima at $82.8 \mathrm{~m}$ depth to the top of a shale/siltstone layer. B3 is characterised by the same lithostratigraphy with B2 but at a lower depth, due to the layer dip angle orientation $\left(45^{\circ} \mathrm{SE}\right)$. The measured profiles could be the result of the heat diffusion due to the uneven heat transfer rate along the direction of the different layers, which are characterised by a dip angle of $45^{\circ} \mathrm{SE}$. 


\section{CONCLUSIONS}

This study presents the analysis of temperature profiles measured by fiber optics in four BHEs in an heterogenous bedrock. The undisturbed ground temperature profiles are characterised by a negative temperature gradient. These profiles can be the result of the heating of the ground by structures located close to the boreholes, as verified also by the 3D numerical model. Temperature profiles during hardening of the grouting material allow to locate extended fracture zones, more than one meter in this specific case. Based on temperature measurements during the recovery phase of a DTRT layers with different mineral content can be detected since they display a different thermal behaviour. The results are in good agreement with those of the borehole televiewer logging method Layers thinner than $1.2 \mathrm{~m}$ or random fractures cannot be identified by this procedure in this case-study. The resolution of the applied procedure is limited by the measurement parameters, spatial resolution and sampling interval.

The influence of the duration of a TRT to the mean ground thermal conductivity and mean borehole thermal resistance is also investigated. In this case-study, thermal conductivity varies less than $15 \%$ for a heating period of 3 months, based on temperature data of the pipe inlet and outlet. The mean borehole thermal resistance decreases of $17 \%$ after the first 30 days of the test. Moreover, the BHE with lower grouting thermal conductivity displays a higher borehole thermal resistance. Measuring the temperature in all the boreholes during the long-duration TRT allows to follow the thermal plume in the heterogenous rock mass. The effect of the distance to the heating source and the effect of the rock heterogeneity are displayed in theese measurements.

Given the increasing number of closed-loop geothermal systems and the wide application of TRTs, it would be of interest to measure the temperature along the BHE length at the undisturbed state, during hardening of the grouting material and during the recovery phase. Alternatively to fiber optic cables, temperature through depth can be measured by lowering down a temperature sensor into the geothermal pipe. Analysing theese profiles could give valuable information about the rock heterogeneity, the influence of the surrounding structures to the ground temperature field, as well as about the rock geothermal reservoir potential. These information could be included in an advanced numerical model, to predict the long-term behaviour of closed-loop geothermal systems and to optimise their efficiency.

\section{REFERENCES}

Carslaw, H.S., and Jaeger, J.C. (1959).Conduction of Heat in Solids, second edition. New York: Oxford University Press.
Charlier, R., Radu, J.-P. and Collin, F. (2001). Numerical mod elling of coupled transient phenomena. Revue Française de Génie Civil, 5(6), 719-741.

Climate-data.org. Climate data for cities worldwide. Last ac cessed 15-10-2015, http://en.climate-data.org/

Collin, F., Li, X.L., Radu, J.-P. and Charlier, R. (2002). Ther mo-hydro-mechanical coupling in clay barriers. Engineering Geology, 64, 179-193.

Erol, S. and François, B. (2014). Efficiency of various grouting materials for borehole heat exchangers. Appl. Therm. Eng., 70, 788-799.

Fujii, H., Okubo, H., and Itoi, R. (2006). Thermal Response Tests Using Optical Fiber Thermometers. GRC Transac tions, 30, 545-551.

Hermans, T., Nguyen, F., Robert, T. and Revil, A. (2014). Ge ophysical methods for monitoring temperature changes in shallow low enthalpy geothermal systems. Energies, 7 (8), 5083-5118.

Hoffmann, L., Müller, M. S., Krämer, S., Giebel, M., Schwotzer, G. and Wieduwilt, T. (2007). Applications of Fibre Optic Temperature Measurement. Proc. Estonian Acad. Sci. Eng., 13 (4), 363-378.

Monier-Williams, M.E., Davis, R.K., Paillet, F.L., Turpening, R.M., Sol, S.J.Y and Schneider, G.W. (2009). Review of Borehole Based Geophysical Site Evaluation Tools and Techniques (Rep. NWMO TR-2009-25). Retrieved from Nuclear Waste Management Organization website: http://www.nwmo.ca/uploads_managed/MediaFiles/ 1770_n wmotr-2009-25boreholebasedgeophysicaltools_ r0d.pdf

Radioti, G., Charlier, R., Nguyen, F. and Radu, J.-P. (2013). Thermal Response Test in Borehole Heat Exchangers Equipped with Fiber Optics. In: Proceedings, International Workshop on Geomechanics and Energy: The Ground as Energy Source and Storage. EAGE, Lausanne, Switzerland, 96-100.

Radioti, G., Delvoie, S., Radu, J.-P., Nguyen, F. and Charlier, R. (2015a). Fractured bedrock investigation by using highresolution borehole images and the Distributed Temperature Sensing technique. In: ISRM Congress 2015 Proceedings - Int'l Symposium on Rock Mechanics, ISRM, Montreal, Can ada.

Radioti, G., Delvoie, S., Sartor, K., Nguyen, F. and Charlier, R. (2015b). Fiber-optic temperature profiles analysis for closed-loop geothermal systems: a case study. In: Proceed ings, Second EAGE Workshop on Geomechanics and Ener gy: The Ground as Energy Source and Storage. EAGE, Cel le, Germany.

Sanner, B., Hellström, G., Spitler, J., and Gehlin, S. (2005). Thermal Response Test - Current Status and World-Wide Application. Proceedings World Geothermal Congress 2005, 24-29.

Sartor, K., Quoilin, S. and Dewallef, P. (2014). Simulation and optimization of a CHP biomass plant and district heating network. Appied Energy, 130, 474-483.

Tinti, F. (2012). The probabilistic characterization of under ground as a tool for the optimization of integrated design of shallow geothermal systems (Doctoral dissertation). Univer sity of Bologna, Italy. 